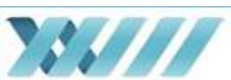

Azienda Ospedaliera Papa Giovanni XXIII Bergamo $\boldsymbol{x}$

\title{
AirWAy MANAGEMENT in A PAEDiATRIC \\ PATIENT WITH A LARGE TONGUE \\ LYNPHANGIOMA
}

t: Euroanaesthesia 2017

\begin{abstract}
Benigni A., Maffioletti M., Locatelli B.G., Sonzogni V., Gritti P. ANAESTHESIA AND INTENSIVE CARE DEPT. - OSPEDALE PAPA GIOVANNI XXIII - BERGAMO (ITALY)
\end{abstract}

Background

Lynphangiomas are malformations of the lynphatic system, often involving the oral cavity, head and neck, and making airway management difficult.

\section{Case report}

We present the case of a 16 months old male affected by a large tongue base mass, confirmed to be a lynphangioma by a previous MRI performed under i.v. sedation three months before. The lesion has grown very quikly from the tongue base, becoming protrusive and leading to dehydratation, malnutrition, infection and aspiration. The breath had become snoring, although respiratory distress never occurred. The patient was scheduled for excision surgery under general anaesthesia. The oral airway approach was not feasible due to the large tongue mass occupying the whole intraoral space. The fiberoptic intubation under sedation was mandatory. The most challenging aspect of this case was to plan a pharmacological strategy to achieve adequate level of sedation while maintaining spontaneous breathing during the procedure. Subsequent to the mask induction by sevoflurane $3 \%$ and $\mathrm{N} 2 \mathrm{O} /$ air $2: 1$, venous access was obtained. A successful nasal fiberoptic intubation by a $3,0 \mathrm{~mm}$ videobronchoscope under sedation and spontaneous ventilation was performed using ketamine $2 \mathrm{mg} / \mathrm{kg}$ iv, atropine $0,02 \mathrm{mg} / \mathrm{kg}$ iv, midazolam $0,1 \mathrm{mg} / \mathrm{kg}$ iv and topical lidocaine $1 \%$. Passive $31 / \mathrm{min}$ flow oxygen via a 4.0 nasotracheal tube was utilized. Desaturation, bleeding and coughing did'nt occur during the procedure. Sialorrhoea was not observed.
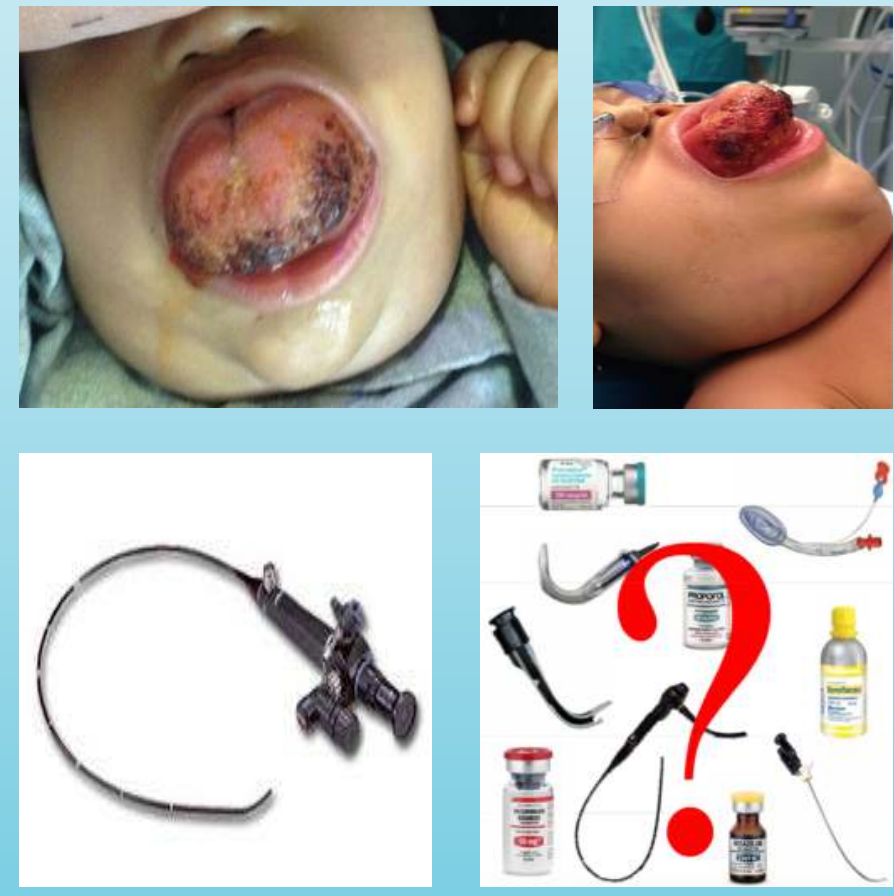

Discussion

Conventional endotracheal intubation methods, including the use of video laringoscope, can be impossible with a mass in oral cavity. In such cases the fiberoptic intubation is the option of choice. A balanced and careful pharmacological approach is critical in order to achieve a good plane of sedation without depressing spontaneous breathing. Ketamine associated with midazolam and topic lidocaine is a safe option for this pourpose.

Learning points

There is limited information on the optimal anaesthetic management for fiberoptic intubation in children with a tongue lymphangioma. The association ketamine/midazolam is a valuable option. 